\title{
THERMAL PERFORMANCE OF THERMOSYPHON FOR DIFFERENT WORKING FLUIDS
}

\begin{abstract}
G. M. Russo ${ }^{\mathrm{a}}$,
L. Krambeck ${ }^{\mathrm{a}}$,

F. B. Nishida ${ }^{a}$,

P. H. D. Santos ${ }^{b}$,

and T. Antonini Alves ${ }^{\mathrm{a}}$

Universidade Tecnológica Federal do Paraná

Departamento Acadêmico de Mecânica

${ }^{\text {a } C a ̂ m p u s ~ P o n t a ~ G r o s s a ~}$

Ponta Grossa, PR, Brasil, CEP 84.016-210

thiagoaalves@utfpr.edu.br

${ }^{\mathrm{b}}$ Câmpus Curitiba

Curitiba, PR, Brasil, CEP 80.230-901

ABSTRACT

In this paper, an experimental investigation was performed of the thermal performance of different working fluids in thermosyphons that can be used in thermal control of electronic equipment. The working fluids were considered acetone, water, ethanol, and methanol. The thermosyphon are manufactured of copper with an outer diameter of $9.45 \mathrm{~mm}$, an inner diameter of $7.75 \mathrm{~mm}$, a total length of $200 \mathrm{~mm}$, whereas an evaporator of 80 $\mathrm{mm}$ length, an adiabatic region of $20 \mathrm{~mm}$ in length and a condenser of 100 $\mathrm{mm}$ in length. They were loaded with $1.39 \mathrm{ml}$ of the working fluid, corresponding to a filling ratio of $40 \%$ of the evaporator volume. Experimental tests were performed in a vertical position considering thermal loads between $5 \mathrm{~W}$ and $25 \mathrm{~W}$. The thermosyphons operated satisfactorily in all the tests. The operating temperature distribution as a function of time and the heat resistance behavior as a function of power dissipation have been presented for each analyzed working fluid. These results indicated that acetone is the working fluid that has the best thermal performance.
\end{abstract}

Received: February 02, 2016

Revised: April 04, 2016

Accepted: May 06, 2016
Keywords: thermosyphon, working fluid, thermal performance, thermal resistance, experimental

\section{NOMENCLATURE}

$h_{l v} \quad$ vaporization latent heat, $\mathrm{J} / \mathrm{kg}$

$k \quad$ thermal conductivity, W/m.K

$M^{\prime} \quad$ Number of Merit, Eq. (1)

\section{Greek symbols}

$$
\begin{array}{ll}
\rho & \text { density, } \mathrm{kg} / \mathrm{m}^{3} \\
\mu & \text { dynamic viscosity, Pa.s }
\end{array}
$$

\section{Subscripts}

l l liquid phase of the working fluid

\section{INTRODUCTION}

Thermosyphons are highly efficient devices, because they use vaporization latent heat of the working fluid. It transports energy as heat with small temperature gradients. They operate in a two-phase cycle and consist of hollow metal tubes filled with a working fluid. They have an operation and manufacture similar to heat pipes, but without the porous structure. Thermosyphons use gravity for circulation of the fluid internally. Thus, thermosyphons have the facility of construction and reduced cost when compared to heat pipes. However, they have restrictions on the operation position.

Thermosyphons have three regions with distinct roles in their operation, they are: evaporator, adiabatic section, and condenser. The evaporator, the lower region of the tube, is heated by a hot source and the working fluid undergoes an evaporation process. This steam, because of the pressure difference, moves to de colder region (condenser). In this region, the steam generated in the evaporator loses energy as heat and is condensed. The working fluid in liquid state flows back to evaporator by gravity, closing the cycle. The adiabatic section is located between the evaporator and the condenser. In this section there is not heat transfer between the thermosyphon and the environment. In some cases, the adiabatic section is absent. A schematic diagram of the thermosyphon operating principle is shown in Fig. 1. More details of the thermosyphons can be found in Peterson (1994), Mantelli (2013), and Reay et al. (2014).

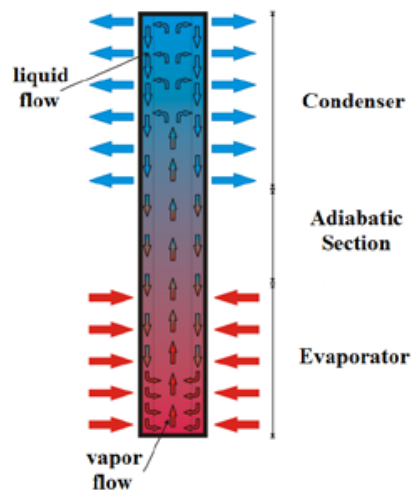

Figure 1. Sketch of the operating principle of thermosyphons. 
As mentioned, the thermosyphons are basically composed of a casing and a working fluid that have to be mechanically and chemically compatible with each other. The casing, in most case, is a hollow tuber, made of metal, glass, or ceramic. The working fluid can vary from liquid metal (mercury, sodium, potassium, lithium), for operation at high temperatures, by passing water to intermediate temperatures, and even helium or nitrogen to operate at low temperatures (Peterson, 1994).

As the operating principle of thermosyphon is based on the evaporation and condensation of the working fluid, it must be carefully chosen. For this purpose, the main selection criterion is that the operating temperature of the thermosyphon is compatible with the boiling temperature of the selected working fluid. In addition, thermophysical properties, such as wettability of the fluid, thermal conductivity, viscosity, surface tension, and vapor pressure, are important and should be evaluated (Mantelli, 2013).

A parameter that associates the working fluid properties with its maximum power transmission capacity as heat is called Number of Merit, according to Reay et al. (2014), can be expressed by

$$
M^{\prime}=\left(\frac{h_{l v} k_{l}^{3} \rho_{l}}{\mu_{l}}\right)^{1 / 4}
$$

where, $h_{l v}$ is the vaporization latent heat of the working fluid, $k_{l}$ is the thermal conductivity of the liquid phase of the fluid, $\rho_{l}$ is the density of the liquid phase of the fluid and $\mu_{l}$ is the dynamic viscosity of the liquid phase of the fluid.

The behavior of Number of Merit, $M^{\prime}$, depending on operating temperature and considering some working fluids is illustrate in Fig. 2.

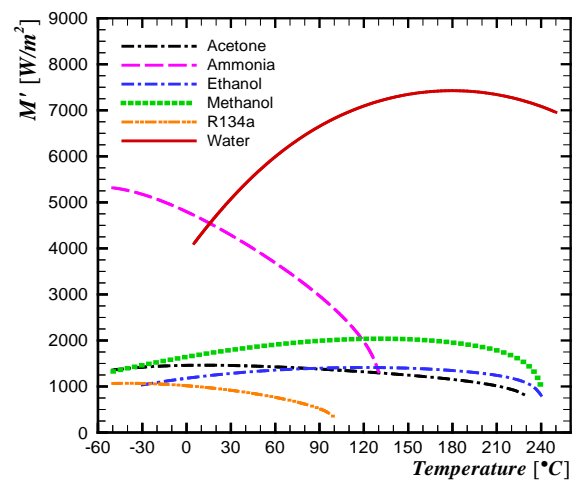

Figure 2. Number of Merit.

In this context, this study was realized an experimental analysis of the thermal performance of different working fluids in thermosyphons. They can be used in thermal control of electronic equipment applications due to their geometrical characteristics. The working fluids analyzed were acetone, deionized water, ethanol, and methanol.

\section{METHODOLOGY}

The methodology used in the cleaning, assembly, the tightness test, the evacuation procedure, and the filling with the working fluid of the thermosyphons was based taking into the consideration the instructions of Santos et al. (2014) and Nishida et al. (2015).

\section{Characteristics of Thermosyphons}

The thermosyphons were produced by copper tubes with an outer diameter of $9.45 \mathrm{~mm}$, an inner diameter of $7.75 \mathrm{~mm}$, and a length of $200 \mathrm{~mm}$. The thermosyphons have an evaporator of $80 \mathrm{~mm}$ in length, an adiabatic region of $20 \mathrm{~mm}$ in length, and a condenser of $100 \mathrm{~mm}$ in length. The thermosyphons were filled with different working fluids with a ratio of $40 \%$ of the evaporator volume. Table 1 shows the main features of the thermosyphons.

Table 1. Main characteristics of the thermosyphons.

\begin{tabular}{|c|c|}
\hline Inner diameter [mm] & 7.45 \\
\hline Outer diameter [mm] & 9.45 \\
\hline Evaporator length [mm] & 80.0 \\
\hline Adiabatic section length [mm] & 20.0 \\
\hline Condenser length [mm] & 100 \\
\hline Volume of working fluid [ml] & 1.39 \\
\hline Filling ratio [\%] & 40.0 \\
\hline
\end{tabular}

\section{Characteristics of studied Working Fluids}

The analyzed working fluids in this experimental investigation were acetone $\left(\mathrm{C}_{3} \mathrm{H}_{6} \mathrm{O}\right)$, deionized water $\left(\mathrm{H}_{2} \mathrm{O}\right)$, ethanol $\left(\mathrm{C}_{2} \mathrm{H}_{6} \mathrm{O}\right)$, and methanol $\left(\mathrm{CH}_{4} \mathrm{O}\right)$. The main thermophysical properties of these chemical substances used as working fluid in the thermosyphons are shown in Table 2. These properties were taken from the library available in software Engineering Equation Solver ${ }^{T M}$ $\left(\mathrm{EES}^{T M}\right)$.

\section{Cleaning of Thermosyphons}

The thermosyphons cleaning was necessary. The reasons for this were to ensure the wettability of the working fluid, the impurity elimination, and the vacuum quality improvement. Thus, all the thermosyphon components need to be thoroughly cleaned, before the working fluid is introduced. For this purpose, first, the casing (copper tube with length of $200 \mathrm{~mm}$ ), the closing lids (milled from a solid copper rod with an outer diameter of $9.45 \mathrm{~mm}$ ), and the capillary (copper tube with an inner diameter of $1 \mathrm{~mm}$ and a length of $40 \mathrm{~mm}$ ) were cleaned with acetone in order to remove larger dirties. After that, theses components were taken to an ultrasonic bath Kondentech $^{T M}$, where remaining immersed in ethylic alcohol during 15 minutes (Fig. 3). 
Table 2. Main thermophysical property of the working fluids.

\begin{tabular}{|l|c|c|c|c|}
\hline \multirow{2}{*}{\multicolumn{1}{c|}{$\begin{array}{c}\text { Property } \\
\text { (em 20}\end{array}$ C e 1 atm) }} & \multicolumn{4}{c|}{ Working Fluid } \\
\cline { 2 - 5 } & Acetone & Water & Ethanol & Methanol \\
\hline Chemical Formula & $\mathrm{C}_{3} \mathrm{H}_{6} \mathrm{O}$ & $\mathrm{H}_{2} \mathrm{O}$ & $\mathrm{C}_{2} \mathrm{H}_{6} \mathrm{O}$ & $\mathrm{CH}_{4} \mathrm{O}$ \\
\hline Molar mass $[\mathrm{kg} / \mathrm{kmol}]$ & 58.08 & 18.02 & 46.07 & 32.04 \\
\hline Specific Heat $[\mathrm{J} / \mathrm{kgK}]$ & 2,131 & 4,183 & 2,396 & 2,505 \\
\hline Vaporization Latent Heat $[\mathrm{J} / \mathrm{kg}]$ & $0.539 \times 10^{6}$ & $2.453 \times 10^{6}$ & $0.928 \times 10^{6}$ & $1.178 \times 10^{6}$ \\
\hline Thermal conductivity $[\mathrm{W} / \mathrm{mK}]$ & 0.1630 & 0.5861 & 0.1708 & 0.1987 \\
\hline Density $\left[\mathrm{kg} / \mathrm{m}^{3}\right]$ & 790.3 & 998.2 & 789.4 & 791.0 \\
\hline Boiling Point $\left[{ }^{\circ} \mathrm{C}\right]$ & 56.2 & 99.7 & 78.4 & 65.0 \\
\hline Critical Pressure $[\mathrm{Pa}]$ & $4.70 \times 10^{6}$ & $22.06 \times 10^{6}$ & $6.27 \times 10^{6}$ & $8.10 \times 10^{6}$ \\
\hline Critical Temperature $\left[{ }^{\circ} \mathrm{C}\right]$ & 235.0 & 374.0 & 241.6 & 240.2 \\
\hline Surface tension $[\mathrm{N} / \mathrm{m}]$ & 0.02334 & 0.07273 & 0.02273 & 0.02267 \\
\hline Dynamic viscosity $[\mathrm{Pa} . \mathrm{s}]$ & 0.0003324 & 0.001002 & 0.001162 & 0.000586 \\
\hline
\end{tabular}

\section{Cleaning of Thermosyphons}

The thermosyphons cleaning was necessary. The reasons for this were to ensure the wettability of the working fluid, the impurity elimination, and the vacuum quality improvement. Thus, all the thermosyphon components need to be thoroughly cleaned, before the working fluid is introduced. For this purpose, first, the casing (copper tube with length of $200 \mathrm{~mm}$ ), the closing lids (milled from a solid copper rod with an outer diameter of $9.45 \mathrm{~mm}$ ), and the capillary (copper tube with an inner diameter of $1 \mathrm{~mm}$ and a length of $40 \mathrm{~mm}$ ) were cleaned with acetone in order to remove larger dirties. After that, theses components were taken to an ultrasonic bath Kondentech $^{T M}$, where remaining immersed in ethylic alcohol during 15 minutes (Fig. 3).

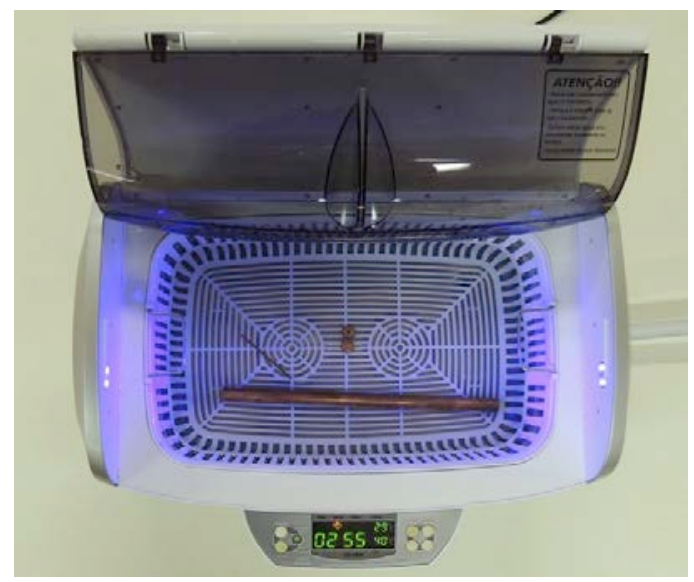

Figure 3. Cleaning the parts of the thermosyphon in the ultrasonic bath.

\section{Assembling of the Thermosyphons}

After the components cleaning process, the thermosyphons can be assembled. The closing lids and the capillary were welded at the end of the thermosyphons, according to the positions showed in Fig. 4. The welding process was performed with the aid of a soldering iron Hikari ${ }^{T M} 300$ and the parts

were brazed using a tin alloy as addition material.

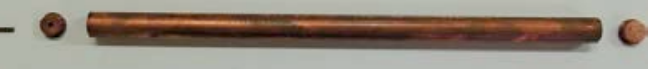

(a) before the welding process

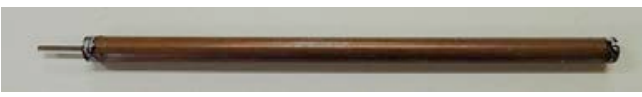

(b) after the welding process

Figure 4. Assembling of the thermosyphon.

\section{Tightness Test}

Tightness test was conducted to verify that there was no fault in the welding process. A manual positive displacement pump, a water container, and a polymeric tube were used to accomplish the test. The polymeric tube makes the connections between the pump and the capillary tube. To this end, the thermosyphons were inserted into the water container and, with the positive displacement pump, air were pumped into the tube. If there were some failure, bubbles would appear in the water. It shows that there were flaws in the solder. In case there was the rise of bubbles, the thermosyphon should be disassembled, cleaned, welded and tested for fault correction in the welding process.

\section{Evacuation Procedure}

The amount of working fluid inserted in the thermosyphon is very important for the thermodynamic cycle inside the tube is completed. If there is not enough fluid, the evaporator will dry that leads to the thermosyphon collapses. As a result, the heat transfer will be interrupted. Before the filling of thermosyphons with the working fluid, it is necessary to make vacuum inside tube. The vacuum was made by a vacuum pump EOS Value ${ }^{T M}$ i260SV (Fig. 5). To this end, a polymeric hose was connected to the capillary of the thermosyphon, joining them to the vacuum pump. The vacuum pump has a flow control valve and a rubber hose that make the link. After that, 
the vacuum pump was switched on. It is recommended that this evacuation procedure has a duration at least of 4 hours. During the vacuum process, the reached internal pressure is $90 \mathrm{mbar}$ $(9 \mathrm{kPa})$ and the saturation temperature of water, related to this pressure, is approximately $43.74^{\circ} \mathrm{C}$.

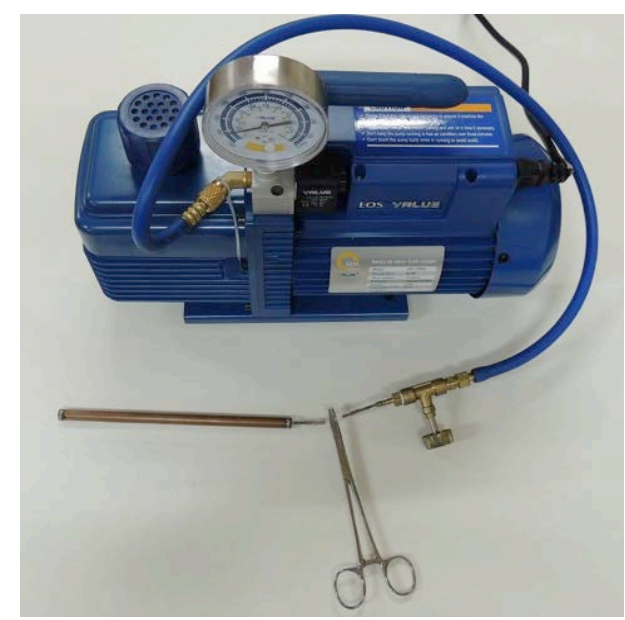

Figure 5. Vacuum pump and the thermosyphon.

\section{Thermosyphon Filling with Working Fluid}

To perform the thermosyphon fillings with the desired working fluid, a small filling station was developed. The filling station is composed of a universal support, a graduated burette (scale of $0.1 \mathrm{ml}$ ) with a capacity of $25 \mathrm{ml}$ Global Glass ${ }^{T M}$, and a forceps (Fig. 6). Each evacuated thermosyphon was coupled to a polymeric hose that makes the connection with the burette. After that, the hose was pinched with the forceps, which prevents that the air enters in the thermosyphon. The burette was completely filled with the working fluid. The next step was the opening of the burette valve carefully. Thus it would not formed any air bubble in the tubing between the burette and the thermosyphon. The forceps was carefully opened to drain the working fluid, until the thermosyphon was charged with the correct quantity. It is emphasized that at the moment of filling, great care must be taken. Otherwise, the thermosyphon vacuum will be lose. If this happens, the entire vacuum process should be perfumed again. The thermosyphons were filled with $1.39 \mathrm{ml}$, which corresponds to $40 \%$ of evaporator volume or a filling ratio of $40 \%$. After the charging, the capillary was clipped with a grip pliers and the end was welded for the completely sealing.

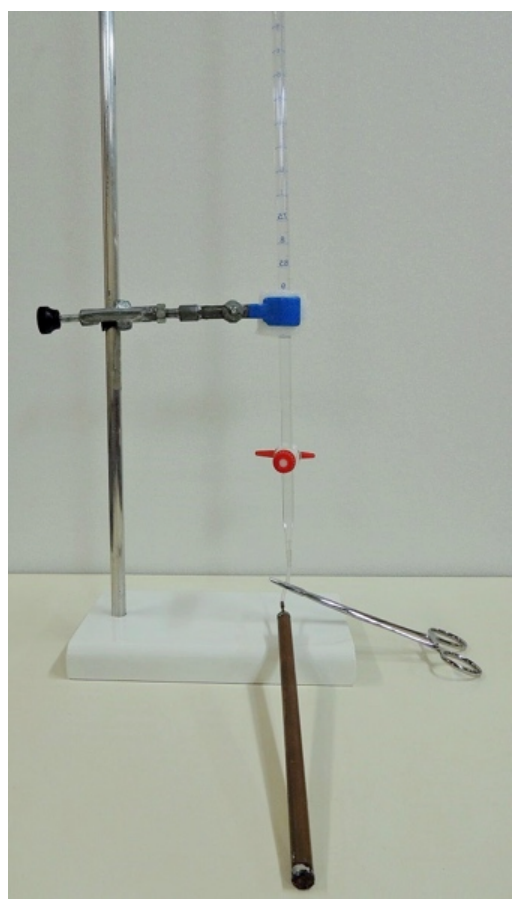

Figure 6. Filling station of the thermosyphons.

\section{EXPERIMENTAL APPARATUS}

The experimental apparatus used for the experimental tests is shown in Fig. 7. It is composed of a power supply unit (Politerm ${ }^{T M}$ POL 16B), a data logger (Agilent ${ }^{\mathrm{TM}}$ 34970A with 20 channels), a Dell $^{T M}$ desktop, and an Ultrar ${ }^{T M}$ DF12038HBL2 fan.

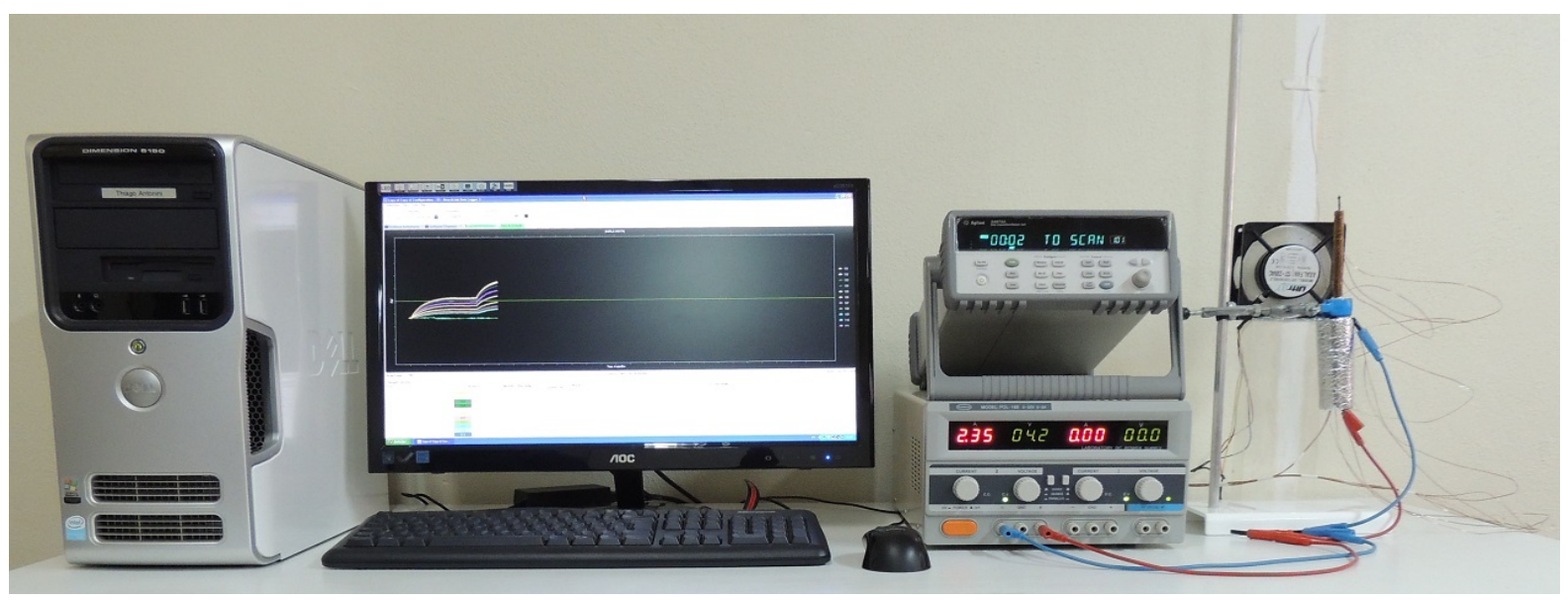

Figure 7. Experimental apparatus. 
K-type Thermocouples (Omega ${ }^{\mathrm{TM}}$ ) were used for the evaluation of the thermal behavior of different working fluids in the thermosyphons. They were fixed on the outer surface of the thermosyphon by a thermosensitive adhesive strip $\left(\right.$ Kapton $^{T M}$ ). There were two thermocouples in the evaporator $\left(T_{\text {evap } 1}\right.$ and $\left.T_{\text {evap, } 2}\right)$, one thermocouple in the adiabatic section $\left(T_{\text {adiab }}\right)$, and three thermocouples in the condenser $\left(T_{\text {cond, } 1}, T_{\text {cond }, 2}\right.$, and $\left.T_{\text {cond }, 3}\right)-$ Fig. 8.

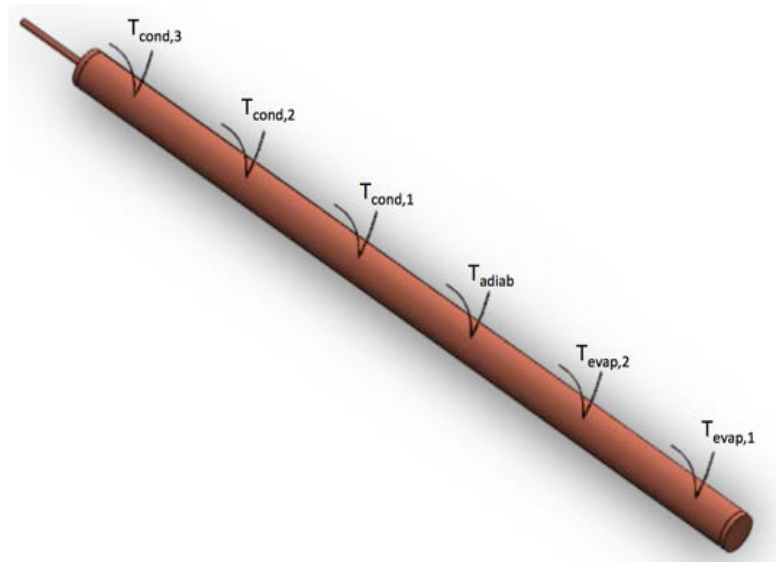

Figure 8. Positioning of the thermocouples.

The heating system of the evaporator was conducted by power dissipation from the passage of an electric current in a nickel-chromium alloy power strip resistor. To ensure that the generated heat by Joule effect was transmitted to the evaporator, a thermal insulation is installed in this region. A glass fiber tape was used in adiabatic section as heat insulation and the cooling system using forced convection air was consisted of a fan in the condenser region.

\section{RESULTS AND DISCUSSIONS}

The results feature the thermal performance of different working fluids in thermosyphons operating upright. The working fluids are acetone, water, ethanol, and methanol. Tests were performed three times with increasing thermal loads of $5 \mathrm{~W}$, ranging from $5 \mathrm{~W}$ to $25 \mathrm{~W}$. The comparative tests showed errors lower $0.5{ }^{\circ} \mathrm{C}$ in mean values. The data uncertainties are estimated to thermocouple temperatures $\left( \pm 2.2{ }^{\circ} \mathrm{C}\right.$ of uncertainty) and power dissipation $( \pm 1 \%$ of uncertainty). The ambient temperature was maintained at $20^{\circ} \mathrm{C} \pm 0.5^{\circ} \mathrm{C}$ by a thermal conditioning system. The thermocouples values are acquired each 5 seconds. Each power was applied for 30 minutes, what all the thermocouples showed a stationary value. For security reasons, the maximum operating temperature established was $120{ }^{\circ} \mathrm{C}$. In the Figure 9, temperatures distributions over the thermosyphons are presented for different working fluids.

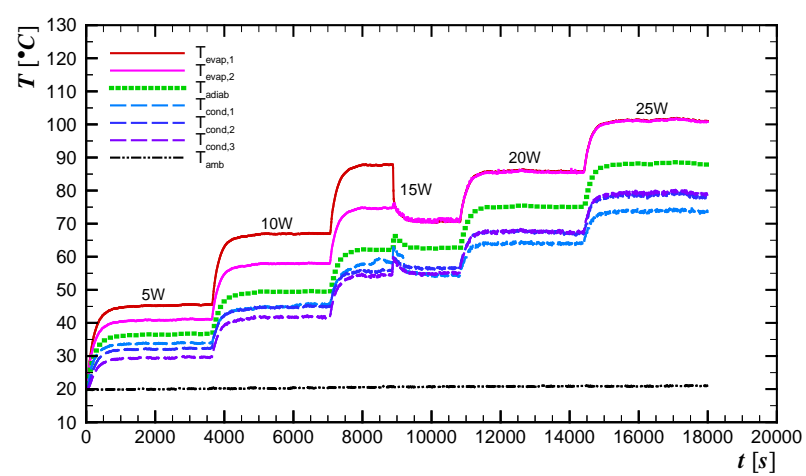

(a) acetone

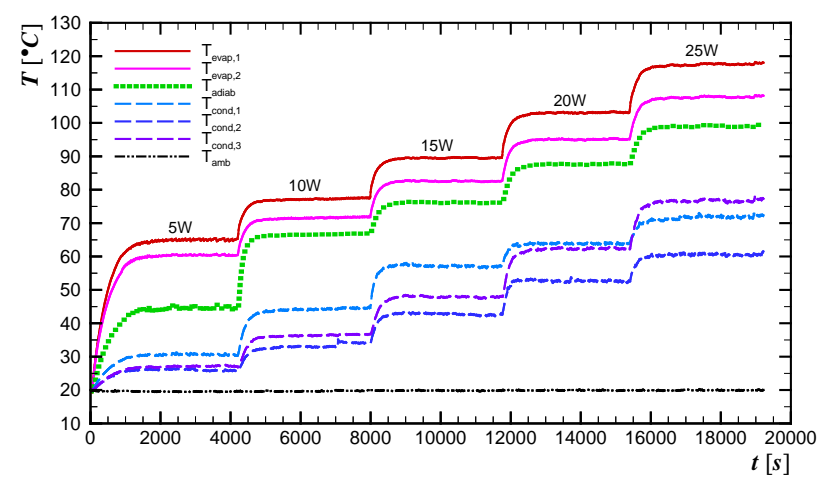

(b) water

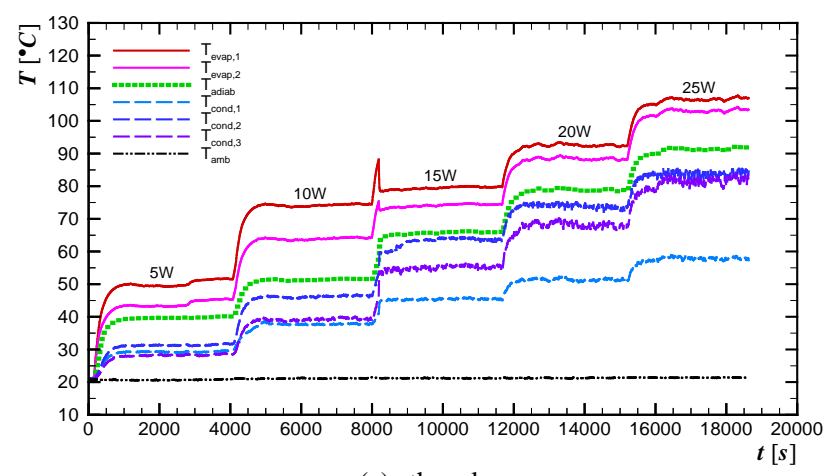

(c) ethanol

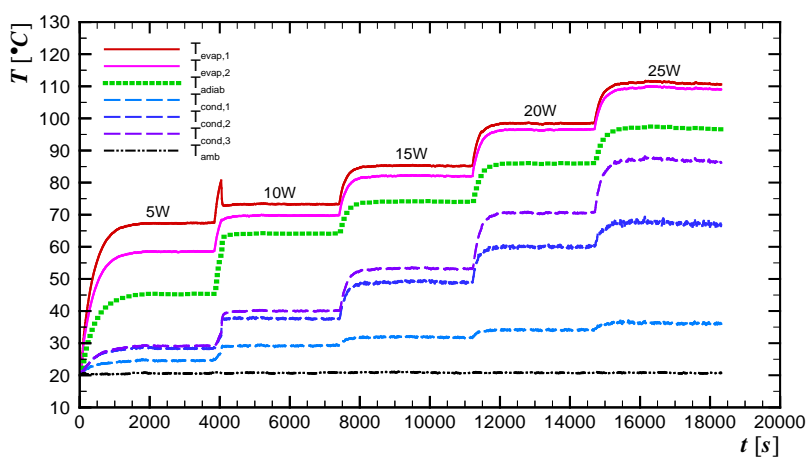

(d) methanol

Figure 9. Temperature distributions of the thermosyphons versus time for various working fluids.

In Table 3 and in Fig.10, the thermal resistance performance of different working fluids in the 
thermosyphons is shown as a function of applied thermal load. The experimental uncertainties are also presented.

Table 3. Thermal resistance in function of applied power.

\begin{tabular}{|c|c|c|c|c|}
\hline \multirow{2}{*}{$\begin{array}{c}\text { Power } \\
\text { [W] }\end{array}$} & \multicolumn{4}{|c|}{ Thermal Resistance [ ${ }^{\mathbf{}} \mathbf{C} / \mathbf{W}$ ] } \\
\cline { 2 - 5 } & Acetone & Water & Ethanol & Methanol \\
\hline \multirow{2}{*}{5} & 2.52 & 6.46 & 3.67 & 4.53 \\
& \pm 0.23 & \pm 0.31 & \pm 0.25 & \pm 0.25 \\
\hline \multirow{2}{*}{$\mathbf{1 0}$} & 1.62 & 3.66 & 2.24 & 2.79 \\
& \pm 0.16 & \pm 0.19 & \pm 0.15 & \pm 0.18 \\
\hline \multirow{2}{*}{$\mathbf{1 5}$} & 1.25 & 2.63 & 1.68 & 2.10 \\
& \pm 0.13 & \pm 0.16 & \pm 0.12 & \pm 0.14 \\
\hline \multirow{2}{*}{$\mathbf{2 0}$} & 1.04 & 2.07 & 1.37 & 1.72 \\
& \pm 0.10 & \pm 0.12 & \pm 0.11 & \pm 0.12 \\
\hline \multirow{2}{*}{$\mathbf{2 5}$} & 0.90 & 1.73 & 1.17 & 1.43 \\
& \pm 0.09 & \pm 0.10 & \pm 0.10 & \pm 0.10 \\
\hline
\end{tabular}

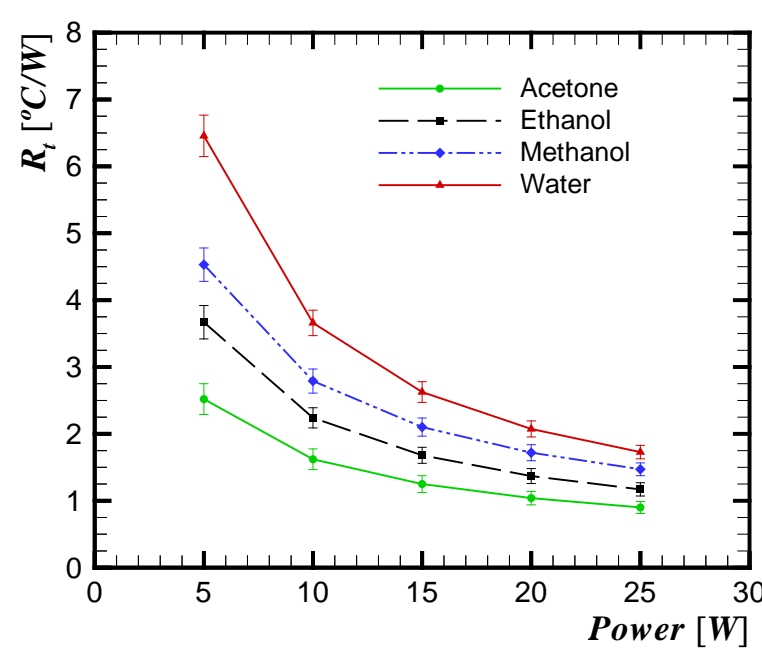

Figure 10. Thermal resistance versus applied power for different working fluids.

As can be seen, regardless of the working fluid used in the thermosyphons, the operating temperature increases and the thermal resistance decreases with the increase of power dissipation. Between the analyzed thermosyphons, acetone is the working fluid that presents the best thermal performance.

\section{CONCLUSIONS}

In this paper, an experimental investigation of the thermal performance of different working fluids (acetone, water, ethanol, and methanol) in thermosyphons was presented. These devices can be applied for the thermal control in electronic equipment. Thermosyphons were tested vertically under thermal loads $5 \mathrm{~W}$ and $25 \mathrm{~W}$ and operated satisfactorily. The working fluid with better thermal performance was acetone.

\section{ACKNOWLEDGEMENTS}

The authors thank the National Council for Scientific and Technological Development (CNPq), as well as the Federal University of Technology Paraná (UTFPR) for the financial support.

\section{REFERENCES}

Mantelli, M. B. H., 2013, Thermosyphon Technology for Industrial Applications, Chapter 11, In: Vasiliev, L. L., and Kakaç, S. (Eds.), Heat Pipes and Solid Sorption Transformations: Fundamentals and Practical Applications, CRC Press.

Nishida, F. B., Marquardt, L. S., Borges, V. Y. S., Santos, P. H. D., and Antonini Alves, T., 2015, Development of a Copper Heat Pipe with Axial Grooves Manufactured using Wire Electrical Discharge Machining (Wire-EDM), Advanced Materials Research, Vol. 1120, pp. 1325-1329.

Peterson, G. P., 1994, An Introduction to Heat Pipes: Modeling, Testing and Applications, (Thermal Management of Microelectronic and Electronic System Series), Wiley-Interscience.

Reay, D. A., Kew, P. A., and McGlen R. J., 2014, Heat Pipe: Theory, Design and Applications, Butterworth-Heinemann.

Santos, P. H. D., Krambeck, L., Santos, D. L. F., and Antonini Alves, T., 2014, Analysis of a Stainless Steel Heat Pipe Based on Operation Limits, International Review of Mechanical Engineering, Vol. 8, pp. 599-608. 